\title{
Comparison between rhinometric variables and nasal airing in children with mouth breathing
}

\author{
Ana Carolina Cardoso de Melo ${ }^{1}$ \\ https://orcid.org/0000-0002-4622-5892 \\ Adriana de Oliveira Camargo Gomes ${ }^{1}$ \\ https://orcid.org/0000-0002-1871-9502 \\ Daniele Andrade da Cunha ${ }^{1}$ \\ https://orcid.org/0000-0002-3987-9740 \\ Wigna Rayssa Pereira Lima Almeida ${ }^{1}$ \\ https://orcid.org/0000-0003-4511-6667 \\ Sandro Junior Henrique Lima² \\ https://orcid.org/0000-0003-3257-2604 \\ Renata Andrade da Cunha ${ }^{3}$ \\ https://orcid.org/0000-0002-5847-8512
}

Hilton Justino da Silva ${ }^{1}$ https://orcid.org/0000-0002-6852-3233

Universidade Federal de Pernambuco, Departamanto de Fonoaudiologia, Programa de Pós-Graduação em Saúde da Comunicação Humana, Recife, Pernambuco, Brasil.

Hospital Barão de Lucena, Recife, Pernambuco, Brasil.

${ }^{3}$ Universidade Federal de Pernambuco, Departamento de Ciências da Saúde, Recife, Pernambuco, Brasil.

Research support source: Coordenação de Aperfeiçoamento de Pessoal de Nível Superior - CAPES. Finantial Code - 001.

Conflict of interests: Nonexistent

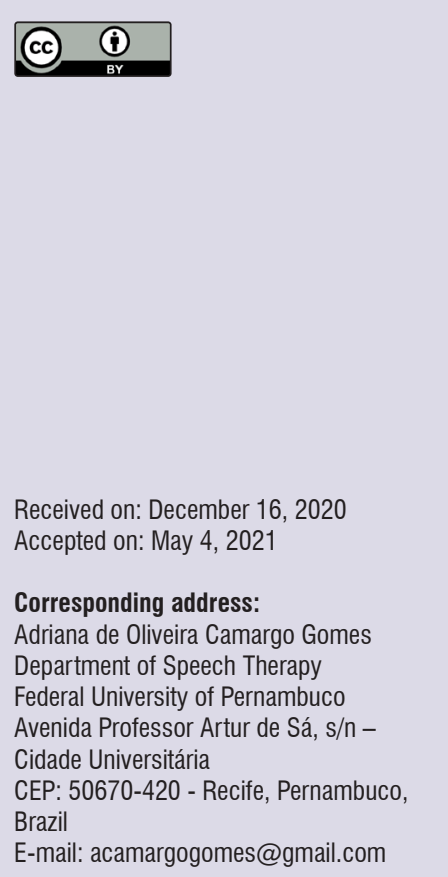

\section{ABSTRACT}

Purpose: to analyze the correlation between the values of nasal aeration and geometry of the nasal cavities, before and after nasal cleansing in children with mouth breathing.

Methods: 20 children aged 4 to 12 years old were chosen. The questionnaire Identification Index of Signs and Symptoms of Oral breathing was applied and nasal patency was assessed by nasal aeration, through the Altmann graded mirror, and the nasal geometry measured by acoustic rhinometry. After nasal cleansing and massage, the same aeration measurements and nasal geometry procedures were performed. Group normality was analyzed using the Shapiro-Wilk test considering the hypothesis of normal distribution whenever $p>0.05$. The Spearman's test was applied to analyze the correlation between variables $(p<0.05)$.

Results: there was a strong and significant correlation between nasal aeration and the corresponding cross-sectional area of the front of the inferior turbinate (CSA2) in the left cavity before cleansing. There were no correlations between the nasal aeration and other rhinometric variables.

Conclusion: there was a correlation between nasal aeration values and the anterior portion of the turbinates, before the massage and nasal cleansing technique, in mouth breathing children. There were no significant differences when the nasal aeration was correlated with other rhinometric variables.

Keywords: Mouth Breathing; Nasal Cavity; Acoustic Rhinometry 


\section{INTRODUCTION}

Mouth breathing can be established when there are anatomical problems that predispose it or when there is persistent changed mode, even after resolution of the initial nasal obstruction ${ }^{1,2}$. Given this situation, a number of changes in the physiological pattern of breathing and postural changes can bring about significant changes in craniofacial structures and their functions ${ }^{3}$. In children, in addition to morphological changes, mouth breathing can lead to frequent fatigue, daytime sleepiness, low appetite and even learning disability ${ }^{4}$.

The assessment of nasal patency by instrumental methods is necessary for the diagnosis and treatment of children with mouth breathing mode. In the beginning of the twentieth century, the investigation of nasal patency through the Glatzel mirror started, which consisted of observing the exhaled air condensing on a cold metal surface, comparing the area of condensation between the nasal cavities ${ }^{5}$. Similarly, Altmann millimeter mirror, which also has a metal plate, but with a smooth side and the other side with millimeter marking, enables measurement of the area marked by the nasal exhalation ${ }^{6}$, which is measured in $\mathrm{cm} 2$.

One technique widely used nowadays and which allows to measure the ratio between the cross-sectional area (CSA) and the distance of different constrictions within the nasal cavity is the Acoustic Rhinometer ${ }^{7-9}$. The method is based on analysis of the reflected sound of the nasal cavity, from the reflection of sound waves, taking into account the properties of this sound in the incidence with the cavity ${ }^{7-10}$. Thus, it is observed that the values of the variables total volume $(0-8 \mathrm{~cm})$ and minimum cross-sectional areas with their respective distances: CSA1 and CSAd1 - corresponding to the nasal valve; CSA2 and CSAd2 - corresponding to the anterior part of the inferior and / or middle turbinate; CSA3 and CSAd3 - corresponding to the posterior part of the middle ${ }^{9}$ or inferior ${ }^{11}$ turbinate.

This technique enables the identification of the loci of constrictions that contribute to nasal resistance thus providing topographical information on the individual profile of the nasal and nasopharyngeal airways. ${ }^{7,10}$ Researches on reference values and to estimate nasal airway obstruction in different etiologies, as well as the effect of distinct pathologies and surgical procedures on nasal cavities in pediatric and adult populations have been reported. ${ }^{7-11}$ The clinical value of acoustic rhinometry rests in its ability to measure nasal geometry, allowing for the discrimination between mucosal functional effects and structural changes related to nasal obstruction, when used in tests before and after treatment ${ }^{8,9}$. Therefore the Acoustic rhinometry is considered a specific test in the investigation of nasal patency ${ }^{10}$.

However, there are maneuvers that allow improving nasal aeration adjusting the breathing function as close as possible to the normality. These techniques to teach the patient breathing through the nose, improving the tonus and adjusting stomatognathic functions encouraging nasal breathing and improve the individual's quality of life. One of these maneuvers consists of a clinical procedure called nasal cleansing and massage, that enable improved nasal permeability and, consequently, a greater bilateral air output, with balancing cavities $^{12,13}$.

With permeability assessments by means of a millimeter mirror and nasal geometry by acoustic rhinometry before and after nasal cleaning, the nasal aeration could be correlated with geometric structural measures of the nasal cavity.

Understanding the importance of these variables for the evaluation and aid diagnosis of nasal patency, the aim of this study is to analyze the correlation between the aeration values and geometry of the nasal cavity, before and after nasal cleansing in children with mouth breathing.

Despite the two techniques measuring different respiratory parameters, the hypothesis of this study is that there is a correlation between sectional areas and nasal volume and nasal aeration, after nasal cleaning and massage.

\section{METHODS}

The research was approved by the Human Research Ethics Committee of the Health Sciences Center of the Federal University of Pernambuco, Brazil, under the approval protocol number 402.660 , according to CNS Resolution 466/12.

Twenty children aged 4 to 12 years with mouth breathing complaint and without nasal obstruction assessed by otorhinolaryngologist were selected. Data collection was carried out after signing the Free Informed Consent (IC) by the child's guardian, authorizing the research. Then, to assist in the functional diagnosis of oral breathing, the Index of Signs and Symptoms of Oral Breathing was applied, with the survey of the main respiratory signs and symptoms, clinically evaluated by a speech therapist specialized in Orofacial Motricity. Of the total amount of the study 
population, $60 \%$ had mouth predominantly breathing during the day and 95\% during the night.

The measurement of nasal aeration was checked by using the Altmann millimeter mirror. Nasal air escape was measured by marking the blurred area with a blue marker before nasal cleaning and red marker, after cleaning. For the record, the marked area was copied in a millimeter special sheet as the mirror and the marked area was calculated in $\mathrm{cm}^{2}$ using the software Image $\mathrm{J}$ (Figure 1).

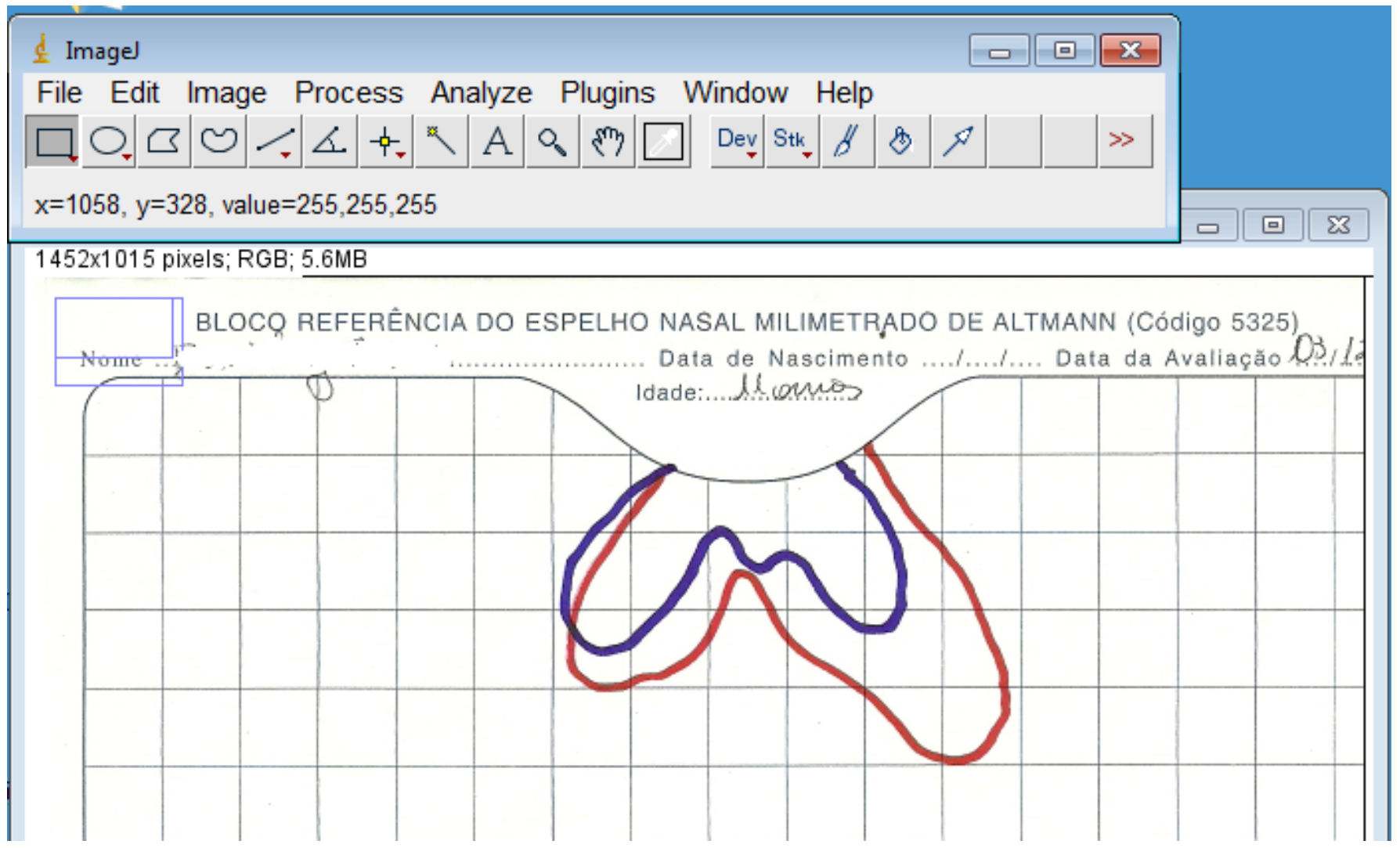

Captions: Bloco de referência do espelho nasal milimetrado de Altmann = Altmann millimeter nasal mirror reference block; Código = code;

Data de Nascimento $=$ Date of birth; Data da avaliação $=$ Date of evaluation; idade $=$ age .

Figure 1. Software Image $\mathrm{J}$ (nasal aeration area in $\mathrm{cm} 2$ ). Blue line= before nasal massage and cleaning; red line= after nasal massage and cleaning.

After collecting the nasal aeration, the examination which measures nasal geometry by Acoustic Rhinometry started to identify the measurement of distances and its respective sectional areas corresponding the nasal valve and the anterior and posterior portions of the turbinates and also the measurement of nasal volume, which favors thereby the identification of the location of constrictions that contribute to nasal resistance ${ }^{9,13,14}$ (Figure 2). The examinations were performed using the Eccovision Acoustic Rhinometer (HOOD Laboratories). 


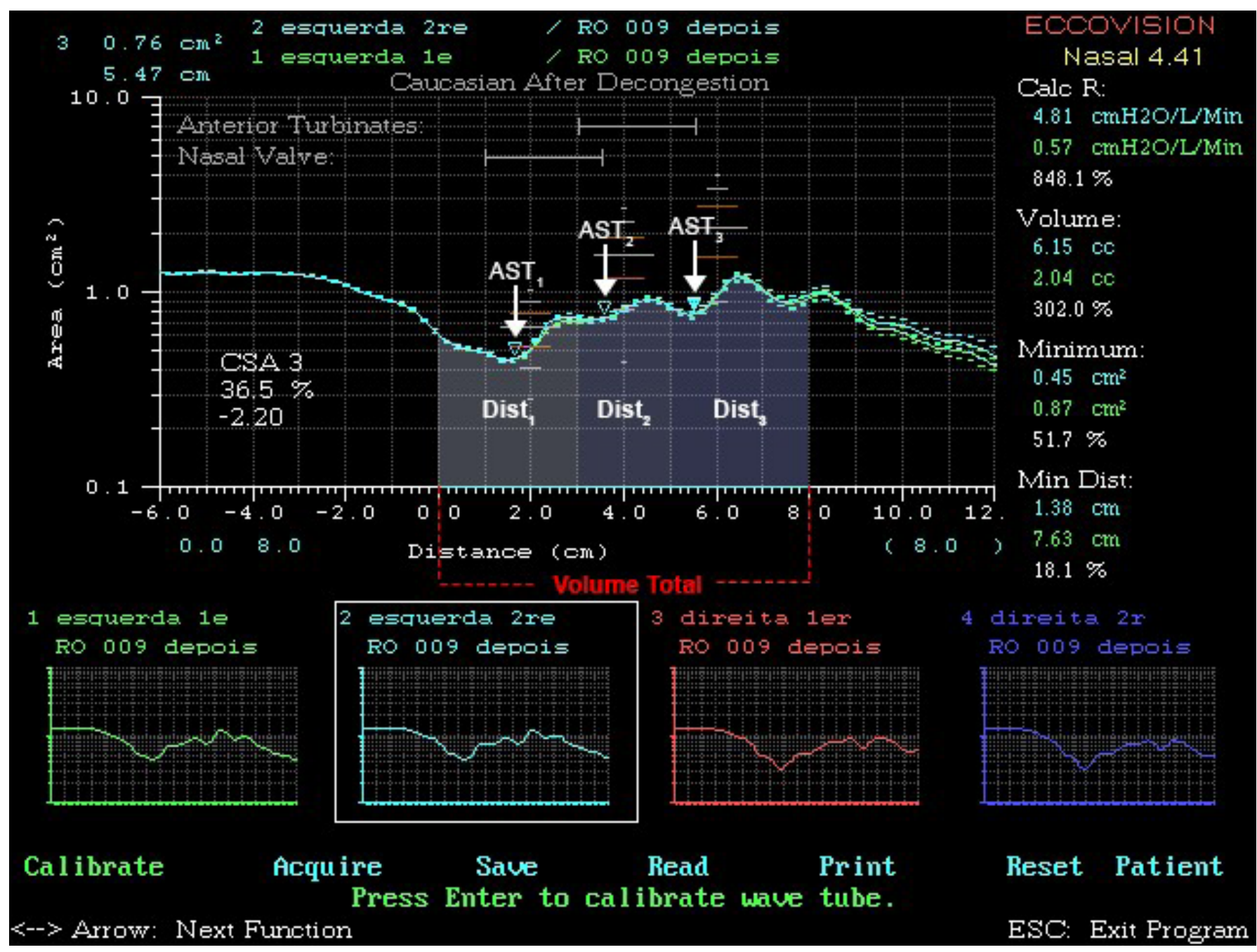

Captions: Esquerda = left nasal cavity; Direita $=$ right nasal cavity; Depois $=$ after nasal massage and cleaning

Figure 2. Acoustic rhinometry examination, with illustrations of the measurement locations of the three nasal cross-sectional areas (AST1,2,3), their respective distances (Dist1,2,3) and considered nasal volume (total volume).

For the examination, the rhinometer tube linked to the nasal adapter, was placed against one nostril; the seal between the nasal adapter and the nostril was achieved by lubricant gel. The methodological due care has been taken in order to avoid to the utmost environmental interference on rhinometric evaluation, minimizing the possible biases in the study ${ }^{7,13}$.

Thus, the temperature and the room noise levels were controlled, the patient had an establishing to the examination room period, the instrument calibration was performed for each patient, and besides care was taken to properly position the rhinometer tube, avoid sound losses and keep the patient's head always stable $^{7,13}$. The child was asked to always look to the computer screen, to maintain the head position during the test. After nasal cleansing and massage ${ }^{12}$ the same procedures were performed.
Then nasal cleansing and massage procedure was performed, in which $2.5 \mathrm{ml}$ of $0.9 \%$ saline solution was poured in by drops, at ambient temperature in each nostril, with the aid of a needleless syringe. Immediately after the saline setting, circular massages were performed with the thumb on the lateral of the nasal region, 10 times on each side. Afterwards, the child blew a nose side at a time in a tissue, removing all secretion. After nasal cleansing and massage the same aeration measurements and nasal geometry procedures were performed.

All procedures (aeration in the mirror, cleaning maneuvers and nasal massage and measurements by acoustic rhinometry) were performed in the same environment. No strategy was used to improve the obtainment of the fogging area of the mirror. 
The areas of the right and left nostrils were measured in isolation, both in the measurements of nasal aeration and in acoustic rhinometry, to facilitate the comparison between the different methods. The area obtained by the mirror was correlated to each portion of the nasal cavity (CSA1, CSA2 and CSA3) individually.

Group normality was analyzed using the Shapiro-Wilk test, considering the hypothesis of normal distribution when $p>0.05$. The Spearman's test was applied to analyze the correlation between variables and a $5 \%$ significance level was assumed.

\section{RESULTS}

In the current study, of the 20 children who were studied, $75 \%$ were males.

As for the variables analyzed in this study, the following results were observed in Tables 1 and 2 .

Table 1. Comparison between total aeration and the left and right nasal cavities, before and after the nasal cleansing and massage

\begin{tabular}{cccccc}
\hline & LN aeration & LN aeration & RN aeration & \multicolumn{2}{c}{ RN aeration } \\
before & after & 0.543 & 0.929 & 0.740 \\
botal Aeration before & rho & 0.911 & 0.540 & $\mathbf{0 . 0 0 0}^{*}$ \\
& p-value & $\mathbf{0 . 0 0 0 ^ { * }}$ & $\mathbf{0 . 0 1 3 ^ { * }}$ & $\mathbf{0 . 0 0 0 ^ { * }}$ & 0.789 \\
Total Aeration after & rho & 0.693 & 0.618 & 0.874 & $\mathbf{0 . 0 0 0}^{*}$ \\
\hline
\end{tabular}

* Spearman's correlation test - significance level at $5 \%$

$\mathrm{LN}=$ left nostril / RN = right nostril; rho= Spearman's correlation coefficient

In Table 1, a strong correlation between the areas of total nasal aeration and aeration areas of the left and right cavities was observed.

Table 2. Correlation between variables: nasal aeration and acoustic rhinometry

\begin{tabular}{|c|c|c|c|c|c|c|c|c|c|c|c|c|c|c|c|c|}
\hline & \multicolumn{8}{|c|}{ LEFT NOSTRIL } & \multicolumn{8}{|c|}{ RIGHT NOSTRIL } \\
\hline & $\begin{array}{c}\text { Vol } \\
\text { before }\end{array}$ & $\begin{array}{l}\text { CSA1 } \\
\text { before }\end{array}$ & $\begin{array}{l}\text { CSA2 } \\
\text { before }\end{array}$ & $\begin{array}{l}\text { CSA3 } \\
\text { before }\end{array}$ & $\begin{array}{c}\text { Vol } \\
\text { after }\end{array}$ & $\begin{array}{l}\text { CSA1 } \\
\text { after }\end{array}$ & $\begin{array}{l}\text { CSA2 } \\
\text { after }\end{array}$ & $\begin{array}{l}\text { CSA3 } \\
\text { after }\end{array}$ & $\begin{array}{c}\text { Vol } \\
\text { before }\end{array}$ & $\begin{array}{l}\text { CSA1 } \\
\text { before }\end{array}$ & $\begin{array}{l}\text { CSA2 } \\
\text { before }\end{array}$ & $\begin{array}{l}\text { CSA3 } \\
\text { before }\end{array}$ & $\begin{array}{c}\text { Vol } \\
\text { after }\end{array}$ & $\begin{array}{l}\text { CSA1 } \\
\text { after }\end{array}$ & $\begin{array}{l}\text { CSA2 } \\
\text { after }\end{array}$ & $\begin{array}{l}\text { CSA3 } \\
\text { after }\end{array}$ \\
\hline \multicolumn{17}{|l|}{ TAB } \\
\hline rho & .033 & .388 & 0.271 & 0.162 & -0.069 & -0.363 & -0.247 & 0.015 & -0.120 & -0.253 & -0.124 & -0.063 & -0.414 & -0.143 & -0.053 & -0.285 \\
\hline $\begin{array}{c}p \text {-value } \\
\text { TAA }\end{array}$ & 0.890 & 0.091 & 0.248 & 0.494 & 0.772 & 0.116 & 0.294 & 0.950 & 0.613 & 0.282 & 0.601 & 0.791 & 0.069 & 0.548 & 0.825 & 0.223 \\
\hline rho & -0.033 & -0.388 & 0.271 & 0.162 & -0.069 & -0.363 & -0.247 & 0.015 & 0.048 & -0.233 & 0.186 & 0.111 & -0.364 & -0.273 & 0.046 & -0.123 \\
\hline$p$-value* & 0.890 & 0.091 & 0.248 & 0.494 & 0.772 & 0.116 & 0.294 & 0.950 & 0.840 & 0.322 & 0.432 & 0.640 & 0.115 & 0.244 & 0.848 & 0.604 \\
\hline \multicolumn{17}{|l|}{ LNAB } \\
\hline rho & 0.203 & 0.110 & 0.448 & 0.329 & 0.179 & 0.176 & 0.130 & 0.230 & -0.071 & -0.163 & -0.104 & -0.065 & -0.342 & -0.042 & 0.053 & -0.217 \\
\hline$p$-value* & 0.391 & 0.645 & 0.048 & 0.157 & 0.450 & 0.459 & 0.585 & 0.329 & 0.767 & 0.493 & 0.663 & 0.787 & 0.140 & 0.860 & 0.823 & 0.359 \\
\hline \multicolumn{17}{|l|}{ LNAA } \\
\hline rho & 0.036 & -0.266 & 0.213 & 0.074 & 0.173 & -0.112 & 0.108 & 0.087 & -0.078 & -0.380 & -0.060 & 0.032 & -0.360 & -0.327 & 0.102 & -0.003 \\
\hline$p$-value* & 0.880 & 0.258 & 0.368 & 0.755 & 0.466 & 0.638 & 0.652 & 0.715 & 0.743 & 0.098 & 0.801 & 0.895 & 0.119 & 0.160 & 0.670 & 0.990 \\
\hline \multicolumn{17}{|l|}{ RNAB } \\
\hline rho & -0.030 & -0.229 & 0.159 & 0.124 & -0.089 & -0.173 & -0.323 & -0.015 & -0.075 & -0.291 & -0.008 & -0.042 & -0.418 & -0.239 & -0.078 & -0.257 \\
\hline$p$-value* & 0.900 & 0.332 & 0.502 & 0.602 & 0.710 & 0.465 & 0.165 & 0.950 & 0.753 & 0.214 & 0.975 & 0.860 & 0.067 & 0.310 & 0.743 & 0.274 \\
\hline \multicolumn{17}{|l|}{ RNAA } \\
\hline rho & 0.000 & -0.271 & 0.119 & 0.141 & -0.107 & -0.227 & -0.378 & 0.035 & 0.170 & -0.075 & 0.283 & 0.156 & -0.269 & -0.208 & -0.014 & -0.165 \\
\hline$p$-value* & 1.000 & 0.248 & 0.618 & 0.552 & 0.654 & 0.336 & 0.101 & 0.885 & 0.474 & 0.752 & 0.227 & 0.510 & 0.252 & 0.380 & 0.952 & 0.486 \\
\hline
\end{tabular}

* Spearman's correlation test - significance level at $5 \%$

CAPTIONS: TAB =total area before nasal cleansing and massage; TAA =total area after nasal cleansing and massage; rho= Spearman's correlation coefficient;

$\mathrm{V}$ ol=total volume; $C S A=$ cross-sectional area; $L N A B=$ left nostril aeration before; $L N A A=$ left nostril aeration after; $R N A B=$ right nostril aeration before; $R N A A=$ right nostril aeration after. 
In Table 2, when the correlation of nasal aeration area with the areas and volumes measured by acoustic rhinometry was demonstrated, there was significant correlation between nasal aeration and CSA2 in the left cavity before cleaning $(p=0.048)$. However, there were no significant differences when the nasal aeration was correlated with other rhinometric variables.

\section{DISCUSSION}

The nasal cavity has a fundamental role in respiratory physiology and a direct relationship with the performance of the stomatognathic system functions ${ }^{15,16}$. It is essential in speech therapy practice to know respiratory function and its structures, which directly influence the diagnosis and treatment of predominantly oral breathing mode. The area of most nasal airflow resistance, and where the narrow segment of the nasal cavity is located, is in the anterior portion, more specifically at the nasal valve area ${ }^{17-19}$.

Instruments and evaluation methods that measure respiratory function have been used increasingly in speech therapy practice. Quantifying this function is still a constant challenge, not only to speech therapists but also to otolaryngologists and allergists. Altmann millimeter mirror is the most used tool for evaluating exhale nasal flow and analyzes the changes in the nasal aeration in patients undergoing certain therapies or changing habits ${ }^{20,21}$. However, it does not provide the data of the nasal area in the inhale process.

It was intended, through this study, to correlate the area measured in the Altmann millimeter mirror, with the areas and volumes identified by acoustic rhinometry, whose technique allows assessment of nasal geometry, providing reliable information about the area and nasal volume and the topographic location of the sectional areas of nasal cavity 7,9 .

The results of this study, from the analysis of 20 children with diagnosis of mouth breathing, showed that when analyzed separately, the nasal aeration areas have strong correlations between them. Significant differences between full aeration before and after nasal cleansing in the left and right cavities were found, as well as in the measured areas in each cavity separately. Some studies ${ }^{6,12}$ point to the same results when correlate the area of the nasal aeration before and after nasal cleansing.

This result confirms the technique of nasal cleaning and massage as beneficial to the mouth breathing patient, promoting greater respiratory freedom and increased nasal aeration ${ }^{22}$, considering the studied group, which consisted of children without nasal obstruction, whose oral breathing was habit. After cleansing, the patient realizes that the nose can be used for breathing, thus providing opportunities to change from oral breathing pattern to nasal pattern ${ }^{23}$.

When the correlation between the variables areas of nasal aeration and areas and volumes of the nasal geometry was tested, it was observed that there was a correlation between the nasal aeration and CSA2 in the left cavity before cleansing. In the other areas and volumes, no correlations between measurements were observed.

This result points to the possible relationship between the sectional area corresponding to the anterior portion of the turbinates and nasal patency, which confirms what has been suggested in other publications, considering that this area, in individuals with nasal obstruction, is the most responsible for the increase of nasal airflow resistance ${ }^{24,25}$.

The non-correlation between that area and the measure of nasal aeration after nasal cleansing and massage can be explained by the fact that the techniques used in this study appraise different respiration parameters: air flow and structural measures. The graded mirror allows evaluating the airflow through the analysis of nasal exhalation. The acoustic rhinometry measures the cross-sectional area of the nostrils, which is independent of airflow, since it must be measured during the breath holding to prevent interference in the results variability of acoustic results ${ }^{24}$. Besides that, the technique of nasal massage and cleansing seems to influence the nasal functionality and not the geometry. It is suggested, therefore, comparative studies with nasal breathers and mouth breathers with and without nasal obstruction to test these correlations.

In addition, it should be noted that the sample was composed of individuals without nasal obstruction. Therefore, the effects of nasal massage can be attributed more to the stimulus to sensitize the passage of air in the nostrils, implying an increase in the flow of nasal air, due to this sensitization than its influence, in this case, on nasal geometry ${ }^{12,13,18,19}$

Studies comparing different nasal permeability measuring instruments ${ }^{5,25}$ also found no correlation between the methods. One of them ${ }^{5}$ had the aim to correlate the results of the visual analog scale and Glatzel mirror in healthy individuals and others without respiratory complaints, and the other ${ }^{25}$ compared different instrumental methods. 
Similarly to the current study, it was found that nasal patency, obviously, largely depends on the geometry of the nasal cavity which has a direct influence on the resistance to air through the nose. However, this research could hold that the nasal internal geometry does not determine the breathing mode and even nasal airflow.

Other research ${ }^{26}$, however, that compared the data of acoustic rhinometry with rhinomanometry, instrumental measurement variables in children and teenagers with allergic rhinitis, obtained significant correlations. Authors ${ }^{27,28}$ suggest that quantitative methods are more sensitive in recognizing changes in the nasal mucosa of subjects with nasal complaints than in healthy ones.

Nevertheless, the nasal cycle phenomenon must be considered because this was not neutralized'. The nasal cycle is characterized by the alternation of periods of greater resistance between the nasal cavities. This occurs due to the variation of predominance of the sympathetic or parasympathetic systems on the mucosa of the right and left nasal cavities, alternately. This physiological alternation persists during oral breathing and nasal occlusion and studies indicate that children up to eleven years of age present a reciprocal nasal cycle, though not always in the classic way, as most adults do ${ }^{27}$.

The variables obtained by the acoustic rhinometry examination still bring a greater accuracy of measurements, being a sensitive test for the evaluation of nasal patency ${ }^{28-30}$. According to the analysis of these variables, significant correlations were found in this study.

However, the mirror also showed up as an efficient tool to quantify changes after the speech therapy procedure of nasal cleansing and massage, strengthening its clinical use for evaluation and monitoring of cases of mouth breathers. Cohort studies should be conducted to verify the effectiveness of nasal cleansing and massage technique in changing the breathing mode from oral to nasal.

It is worth mentioning that a possible limitation of this study was not to control the variations inherent to the nasal cycle ${ }^{7,26}$. However, for this, it would be necessary to use a vasoconstrictor drug, which would make the study objective related to the effect of massage and nasal cleaning impossible.

Acoustic rhinometry is indicated, in this study, as an important instrument to further evaluation in monitoring mouth breathers in speech therapy besides its established use as an evaluation method of nasal obstruction. This current study suggests that acoustic rhinometry can be a complementary instrument in speech therapy for evaluation and aid in the diagnosis and treatment of children with mouth breathing and confirmed the effect of the nasal cleansing and massage technique, highly used in speech therapy practice.

\section{CONCLUSION}

A significant correlation between the variable of nasal aeration and acoustic rhinometry in the area corresponding to the second constriction of the left nasal cavity before nasal cleansing and massage technique has been found. There were no correlations between the nasal aeration and other rhinometric variables.

\section{REFERENCES}

1. Pacheco AB, Silva AMT, Mezzomo CL, Berwig LC, Neu AP. Relação da respiração oral e hábitos de sucção não-nutritiva com alterações do sistema estomatognático. Rev. CEFAC. 2012;14(2):281-9.

2. Alqutami J, Elger W, Grafe N, Hiemisch A, Kiess W, Hirsch C. Dental health, halitosis and mouth breathing in 10-to-15year old children:na potential connection. Eur J Paed Dent. 2019;20(4): 274-9.

3. Hsu Y, Lan M, Huang Y, Kao M, Lan M. Association between breathing route, oxygen desaturation and upper airway morphology. Laryngoscope. 2021;131: e569-64.

4. Di Ninno CQM, Figueiredo JSS, Bosco RLG, Cruz SMS, Godinho RN, Miranda ICC. Obstrução nasal total: estudo morfofuncional de um caso de sinéquia de palato mole e paredes faríngeas pós blastomicose. Rev. CEFAC. 2012;14(5):963-70.

5. Brecvovici S, Roithmann R. Modified glatzel mirror test reproducibility in the evaluation of nasal patency. Braz $\mathrm{J}$ Otorhinolaryngol. 2008;74(2):215-22.

6. Cunha AD, Silva HJ, Moraes KJR, Cunha RA, Régis RMFL, Silva EGF et al. Aeração nasal em crianças asmáticas. Rev. CEFAC. 2011;13(5):783-9.

7. Gomes AOC, Sampaio-Teixeira ACM, Trindade SHK, Trindade IEK. Nasal cavity geometry of healthy adults assessed using acoustic rhinometry. Braz J Otorhinolaryngol. 2008;74(5):746-54. 
8. Trindade IEK, Castilho RL, Sampaio-Teixeira ACM, Suedam-Trindade IK, Silva Filho OG. Effects of orthopedic rapid maxillary expansion on internal nasal dimensions in children with cleft lip and palate assessed by acoustic rhinometry. J Craniofac Surg. 2010;21(2):306-11.

9. Trindade IEK, Gomes AOC, Fernandes MBL, Trindade SHK, Silva Filho OG. Nasal airway dimensions of children with repaired unilateral cleft lip and palate. The Cleft Palate Craniofac J. 2015;52(5):512-6.

10. Melo ACC, Gomes AOC, Cavalcanti AS, Silva HJ. Acoustic rhinometry in mouth breathing patients: a systematic review. Braz J Otorhinolaryngol. 2015;81(2):212-8.

11. Trindade IEK, Conegliam PCP, Trindade SHK, Dias $\mathrm{NH}$, Sampaio-Teixeira ACM. Internal nasal dimensions of adults with nasal obstruction. Braz J Otorhinolaryngol. 2013;79(5):575-81.

12. Melo FMG, Cunha AD, Silva HJ. Avaliação da aeração nasal pré e pós realização de manobras de massagem e limpeza nasal. Rev. CEFAC. 2007;9(3):375-82.

13. Melo ACC, Gomes AOC, Cunha DA, Lima SJH, Lima WRP, Cunha RA et al. Change in the nose areas in children with mouth breathing after nasal cleansing and massage. CoDAS. 2016;28(6):770-7. Doi:10.1590/2317-1782/20162015172.

14. Trindade IEK, Gomes AOC, Sampaio-Teixeira ACM, Trindade SHK. Adult nasal volumes assessed by acoustic rhinometry. Braz $\mathrm{J}$ Otorhinolaryngol. 2007;73(1):32-9.

15. Paiva JB, Freire-Maia BAV, Neto JN, Di Francesco RC, Voegels RL. Evaluation of children nasal geometry, employing accoustic rhinometry. Braz J Otorhinolaryngol. 2010;76(3):355-62.

16. Menezes VA, Cavalcanti LL, Albuquerque TC, Garcia AFG, Leal RB. Mouth breathing within a multidisciplinary approach: Perception of orthodontists in the city of Recife, Brazil. Dental Press J Orthod. 2011;16(6):84-92.

17. Wen J, Inthavong K, Tu J, Wang S. Numerical simulations for detailed airflow dynamics in a human nasal cavity. Resp Physiol Neurobiol. 2008;161: 125-35.

18. Mlynski G, Grutzenmacher S, Plontke S, Mlynski B, Lang C. Correlation of nasal morphology and respiratory function. Rhinology. 2001;39(4):197-201.
19. Nigro CEN, Nigro JFA, Mion O, Mello Jr JF. Nasal valve: anatomy and Physiology. Braz J Otorhinolaryngol. 2009;75(2):305-10.

20. Degan VV, Puppin-Rontani RM. Aumento da aeração nasal após remoção de hábitos de sucção e terapia miofuncional. Rev. CEFAC. 2007;9(1):55-60.

21. Bassi IB, Franco LP, Motta AR. Eficácia do emprego do espelho de Glatzel na avaliação da permeabilidade nasal. Rev. Soc. Bras. Fonoaudiol. 2009;14(3):367-71.

22. Cunha DA, Silva HD. Terapia fonoaudiológica em respiração Oral (como eu trato). In: Marchesan $I Q$, Silva HD, Berretin-Felix G, editors. Terapia Fonoaudiológica em Motricidade Orofacial. São José dos Campos, SP: Pulso Editorial. 2012. p. 87-94.

23. Krakauer LH. Terapia do respirador oral. In: Krakauer LH, Di Francesco RC, Marchesan $I Q$, editors. Respiração Oral: abordagem interdisciplinar. São José dos Campos, SP: Pulso. 2003. p.119-25.

24. Melo ACC, Gomes AOC, Silva HJ. Correlation of three variables describing nasal patency (HD, MCA, NOSE score) in healthy subjects. Resenha. Disturb. Comun. 2014;26(2):417-9.

25. Braun T, Rich M, Kramer MF. Correlation of three variables describing nasal patency $(H D$, MCA, NOSE score) in healthy subjects. Braz J Otorhinolaryngol. 2013;79(3):354-8.

26. Wandalsen GF, Mendes AL, Solé D. Correlation between nasal resistance and different acoustic rhinometry parameters in children and adolescents with and without allergic rhinitis. Braz J Otorhinolaryngol. 2012;78(6):81-6.

27. Gallego AJ, Cavallari FEM, Valera FCP, Demarco RC, Anselmo-Lima WT. Study of nasal cycles in children by acoustic rhinometry. Am J Rhinol. 2006;20(6):560-2.doi: 10.2500/ ajr.2006.20.2951.

28. Numminen J, Ahtinen $M$, Huhtala $H$, Rautiainen MEP. Comparison of rhinometric measurements methods in intranasal pathology. Rhinology. 2003;41:65-8.

29. Salgueiro AGNS, Silva ASC, Araújo BMAM, Yamashita RP, Trindade IEK. Comparative analysis of velopharyngeal activity assessed by acoustic rhinometry and rhinomanometry CoDAS. 2015;27(5):464-71. 
30. Malizia V, Fasola S, Ferrante G, Cilluffo G, Gagliardo $\mathrm{R}$, Landi $\mathrm{M}$ et al. Effect of beclomethasone dipropionate and cetirizine on acoustic rhinometry parameters in children with perennial allergic rhinitis: a randomized controlled trial. J Investig Allergol Clin Immunol. 2018;28(6):392-400. doi: 10.18176/jiaci.0263 